\title{
The effect of boron incorporation on the thermo-oxidative stability of phenol-formaldehyde resin and its pyrolyzate phase
}

\author{
Jie Ding ${ }^{1, a}$, Zhixiong Huang ${ }^{1, b}$, Yan Qin ${ }^{1, c}$, Haitao Luo ${ }^{1, d}$, Jiawei Mao ${ }^{1, \mathrm{e}}$ \\ ${ }^{1}$ School of Materials Science and Engineering, Wuhan university of technology, Wuhan, 430070, \\ China

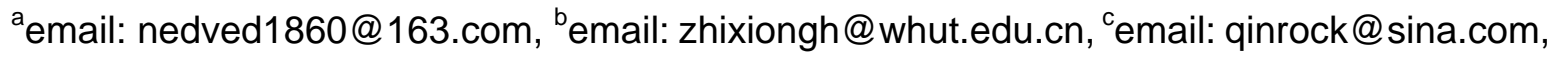 \\ demail: 13102526@qq.com, eemail: 270178281@qq.com,
}

Keywords: phenol-formaldehyde resin; boron; modified; thermo-oxidative stability; pyrolyzate

\begin{abstract}
The thermo-oxidative degradation behavior of the B-PF was studied using thermal gravimetry analysis (TGA-DTG) method. Compared with the unmodified resin (PF), the temperature at the maximum decomposing rate of the $\mathrm{B}-\mathrm{PF}$ resin increases by $54{ }^{\circ} \mathrm{C}$ and its oxidative residues yield at $1000{ }^{\circ} \mathrm{C}$ enhances by 17.99 percent. The pyrolyzate of B-PF were further analyzed by XPS and XRD analysis. The analysis indicates that the boron element reacts with the air or oxygen-containing volatiles to generate boron nitride and boron oxide at elevated temperatures. In addition, incorporating boron into the carbon lattice increases the crystallite height and decreases the interlayer spacing.
\end{abstract}

\section{Introduction}

The rapid development of the applications of PF has attracted the attention of many researchers to improve its related properties. To improve the high-temperature ablation and charring yield of PF, the incorporation of boron, phosphorus, silicon, titanium or other compounds into the backbone of phenolic resin has been reported by many researchers [1-3]. For the excellent performances, such as thermal stability, mechanical strength and dielectric properties, modified phenolic resin (B-PF) obtained by introducing boron into the main chain of a phenolic resin is the earliest studies.

According to the literature [4-5], the condensation product of salicylalcohol and boric acid consists principally of phenol borate and some salicylalcohol borate. It was studied that born tended

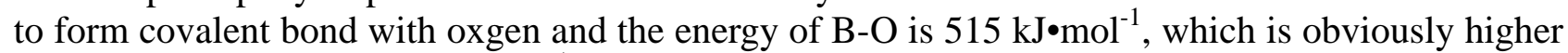
than that of $\mathrm{C}-\mathrm{C}$ bond $\left(345 \mathrm{~kJ} \cdot \mathrm{mol}^{-1}\right)$ [6].

In this work, the comparison of the thermal oxidation stability between phenol-formaldehyde resin (PF) and boron-containing phenol-formaldehyde resin (B-PF) was investigated using TG-DTG analysis. The thermal oxidative residues of the born modified resin were also analyzed by XRD and XPS.

\section{Experimental}

\section{Raw materials}

THC-400 was a kind of boron-containing phenol-formaldehyde resin (B-PF) from Shanxi Taihang Impede fire Polymer Limited Company, China. The ordinary phenol-formaldehyde resin (PF) was prepared with conventional method [7] for comparison.

\section{The preparation of specimens}

The B-PF and PF resin gel were obtained after being pretreated in furnace at $110{ }^{\circ} \mathrm{C}$. Then, in the vulcanizing machine, the gel was hot-pressed in a stainless steel mould at a pressure of $10 \mathrm{MPa}$ for $6 \mathrm{~h}$ and temperatures ranging from 110 to $150{ }^{\circ} \mathrm{C}$. Finally, the thermoforming samples were heat-treated at different temperatures in the range of $180-200{ }^{\circ} \mathrm{C}$ for $3 \mathrm{~h}$.

STA449c/3/GA (NETZSCH Inc.,Germany) typed thermal gravity (TG-DTG) analyzer was used 
for the thermogravimetric analysis. These measurements were carried out under the air and in the temperature range of $90-1000{ }^{\circ} \mathrm{C}$ at the constant heating rates of $10{ }^{\circ} \mathrm{C} \cdot \mathrm{min}^{-1}$. An $\mathrm{X}$-ray photoelectron spectroscopy (XPS) instrument, VG Multilab 2000, was used to investigate the bond-valence evolution of boron. Curve fitting of the $\mathrm{B}_{1 \mathrm{~s}}$ band was performed, assuming a Gaussian peak. The phase composition was analyzed by a D8 Advance X-ray diffraction device (Cu Ka radiation, D/max-RB, Japan).

\section{Results and discussion}

\section{Thermo-oxidative stability of B-PF}

The thermo-oxidative stability of PF and B-PF in air atmosphere was investigated by TGA. The TG and the derivative thermal gravimetric (DTG) curves are shown in Fig. 1. The pyrolysis processes of cured PF and B-PF are similar, in both of which three major reaction regions consist. The initial decomposition temperature of $\mathrm{PF}$ and $\mathrm{B}-\mathrm{PF}$ is about $167^{\circ} \mathrm{C}$ and $404^{\circ} \mathrm{C}$ (Table 1), respectively. It indicates that the oxidation resistance of the phenolic resin is significantly improved owing to the introduction of boron element. This can be attributed to the higher bond energy of B-O, which is $515 \mathrm{~kJ} \mathrm{~mol}^{-1}$, obviously higher than C-C bond $\left(345 \mathrm{~kJ}^{\circ} \mathrm{mol}^{-1}\right)$.

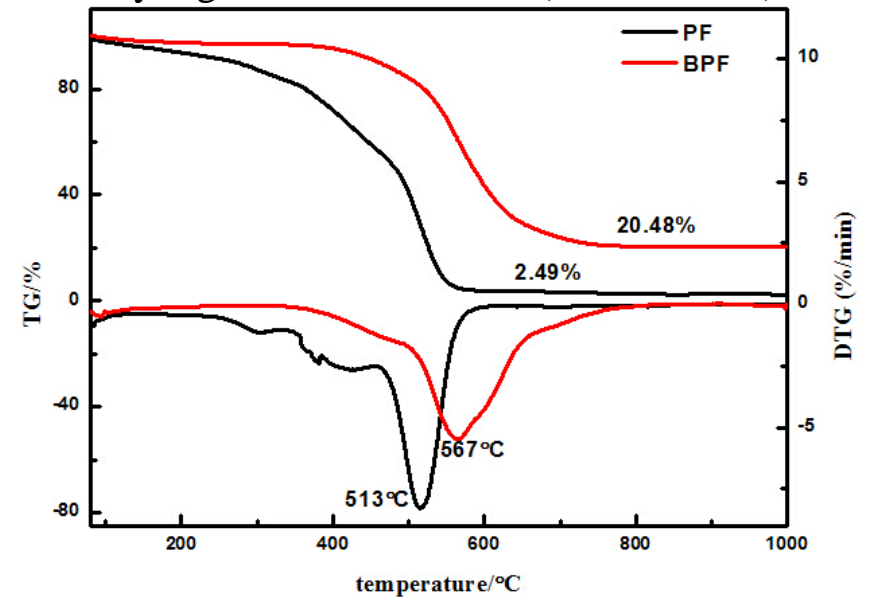

Fig.1. TG and DTG curves of ordinary PF and B-PF under an air atmosphere

Table 1 Thermogravimetric analysis data of the cured B-PF and PF under an air atmosphere.

\begin{tabular}{ccccc}
\hline Resin & $\mathrm{T}_{5 \%}\left({ }^{\circ} \mathrm{C}\right)$ & $\mathrm{T}_{10 \%}\left({ }^{\circ} \mathrm{C}\right)$ & $\mathrm{T}_{\mathrm{d}}\left({ }^{\circ} \mathrm{C}\right)$ & $\mathrm{R}_{1000^{\circ} \mathrm{C}}(\%)$ \\
\hline $\mathrm{B}-\mathrm{PF}$ & 404 & 461 & 567 & 20.48 \\
PF & 167 & 271 & 513 & 2.49 \\
\hline
\end{tabular}

With the polymer network gradually oxidated, many kinds of volatiles including $\mathrm{CO}, \mathrm{CO}_{2}$ etc. are released out, resulting in the gradual decrease of weight. Whereas above $500^{\circ} \mathrm{C}$ dramatic changes can be obviously observed, during to the collapse of the network and deformation of polyaromatic structure.

Although only a small amount of boron is introduced into the backbone of the phenolic resin, the temperature at the maximum decomposing rate of $\mathrm{B}$-PF respectively is $567^{\circ} \mathrm{C}$, an increase of $54^{\circ} \mathrm{C}$ compare to that of the unmodified phenolic resin. And the maximum pyrolysis rate of B-PF respectively is $5.44 \% / \mathrm{min}$, a decrease of $8.23 \% / \mathrm{min}$ compare to that of the unmodified phenolic resin. Moreover, the oxidative residues yield of the $\mathrm{B}-\mathrm{PF}$ at $1000^{\circ} \mathrm{C}$ is $20.48 \%$, which is also $17.99 \%$ higher than the latter.

\section{Characterizations of B-PF thermal oxidative residues}

To further verify the occurrence of thermal reactions between boron and the air (or oxygen-containing volatiles), the oxidative pyrolyzate of the B-PF was studied by the XPS and XRD analysis. All samples were the products after TG analysis.

The XPS spectrum of boron modified PF matrix treated at $1000^{\circ} \mathrm{C}$ (Fig. 2) displays two peaks on the $\mathrm{B}_{1 \mathrm{~S}}$ pattern: (i) peak 1 (186.50 eV): $\mathrm{BN}$; (ii) peak 2 (193.92 eV): $\left[\mathrm{BO}_{3}\right]$ glass. Because $\mathrm{B}_{2} \mathrm{O}_{3}$ will melt above $450^{\circ} \mathrm{C}$ and form a glass phase structure, the $\left[\mathrm{BO}_{3}\right]$ triangle is located at higher 
binding energy.

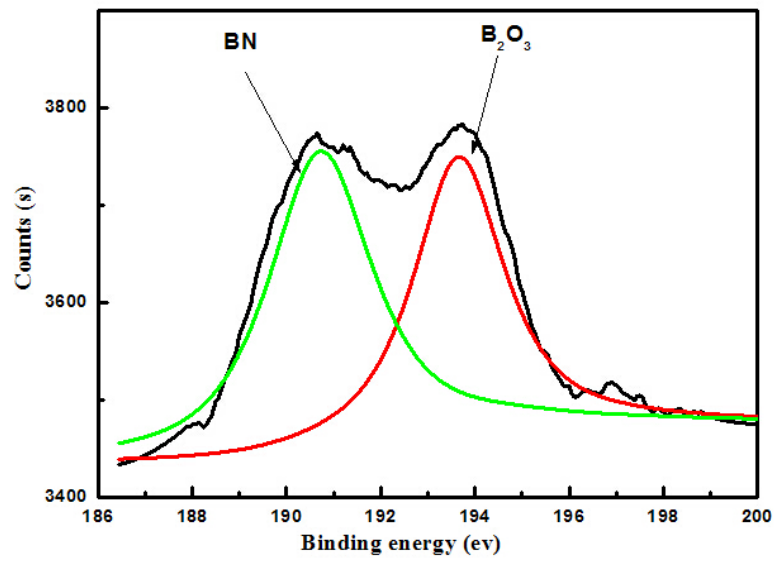

Fig. 2. $\mathrm{B}_{1 \mathrm{~s}} \mathrm{XPS}$ spectrum for the cured B-PF after treating at $1000^{\circ} \mathrm{C}$

The X-ray powder diffraction patterns of both samples pyrolyzated at $1000^{\circ} \mathrm{C}$ are shown in Fig. 3. Two broad maxima, corresponding to (002) and (10) reflections of a turbostratic carbon structure, are observed at $2 \theta$ angles of about $24^{\circ}$ and $44^{\circ}$, respectively. Although diffraction patterns of C-B-PF are similar to that of C-PF, obvious difference can be seen. Some new peaks appear at $2 \theta=14.6^{\circ}, 27.9^{\circ}, 39.9^{\circ}$ in C-B-PF curve, corresponding to (222), (310) and (420) reflection of lattice plane for $\mathrm{B}_{2} \mathrm{O}_{3}$. It indicates that $\mathrm{B}_{2} \mathrm{O}_{3}$ should be formed during the pyrolyzation of the phenolic resin. The oxygen atom may come from the oxygen of the atmosphere or the resin itself. $\mathrm{B}_{2} \mathrm{O}_{3}$, with the melting point of $450^{\circ} \mathrm{C}$, could be converted into a glassy liquid phase containing a large number of $\mathrm{BO}_{3}$ triangles above this temperature. The glassy liquid phase could fill the pores produced by low molecular volatile substance (mainly for $\mathrm{CO}, \mathrm{CO}_{2}$ ) and improve the compactness properties of the resin.
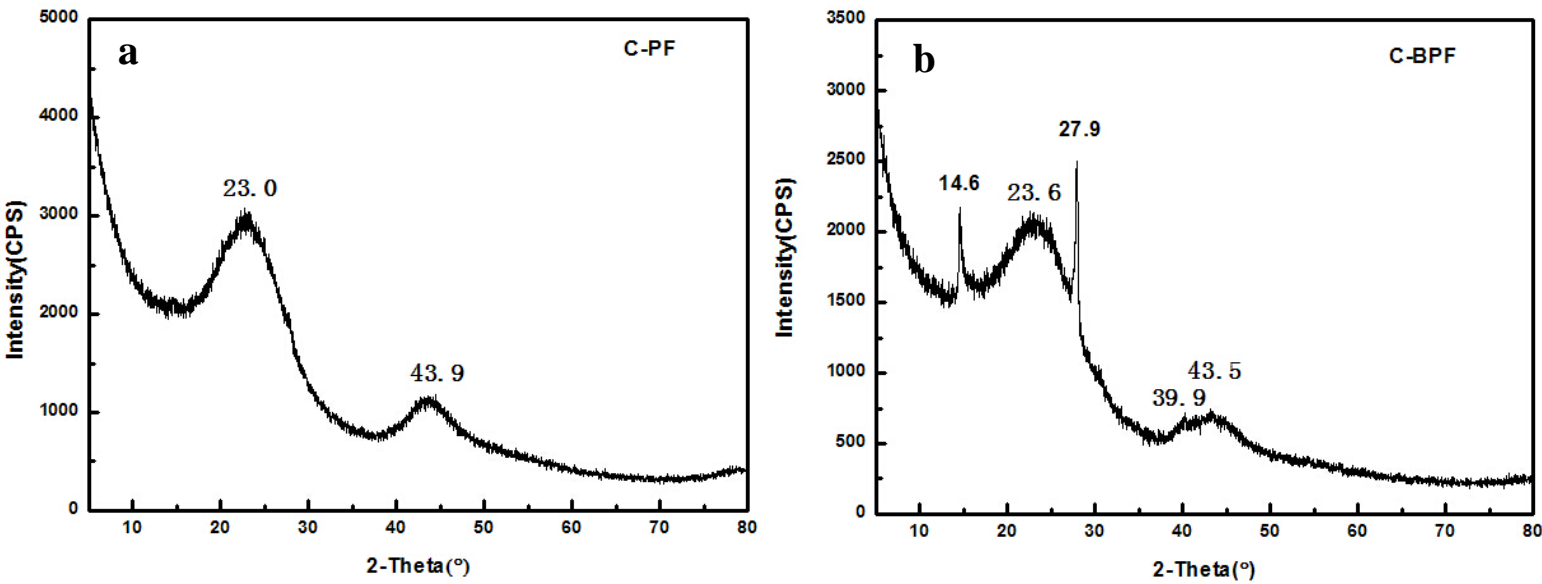

Fig.3. Normalized XRD patterns of C-PF and C-B-PF thermal oxidative residues

a) C-PF, b) C-B-PF.

Despite the non-graphitizable character of both pyrolyzated products, the crystallinity was greatly improved due to the presence of boron. Boron incorporation has a little effect to the parameters of diffraction peak and crystallite sizes. Table 2 lists crystal parameters of the C-PF and C-B-PF. The basal spacing $\mathrm{d}_{002}$ for the carbides is calculated according to the Bragg formula $\lambda=2 \mathrm{~d}_{002} \sin \theta$. The crystallite size $\left(\mathrm{L}_{\mathrm{a}}\right)$, the stacking size of carbon basal planes ( $\mathrm{L}_{\mathrm{c}}$ crystal thickness) can be calculated by the following expressions, respectively:

$\mathrm{L}_{\mathrm{a}}=9.5 /\left(\mathrm{d}_{002}-3.354\right)$;

$\mathrm{L}_{\mathrm{c}}=\mathrm{K} \lambda / \mathrm{B} \cos \theta$;

Where $\lambda=1.5406 \mathrm{~nm}, \mathrm{~K}$ is the apparatus constant $(=1.0)$, and $\mathrm{B}$ is the half value width in radians of the X-ray diffraction intensity (I) vs. $2 \theta$ curve.

Table 2 Parameters of 002 and 10 diffraction peaks for pyrolyzated PF and B-PF.

Sample $2 \theta(002)$ $2 \theta(100)$ $\mathrm{d}_{002} / \mathrm{nm}$ $\mathrm{L}_{\mathrm{a}} / \mathrm{nm}$ $\mathrm{L}_{\mathrm{c}} / \mathrm{nm}$ 


\begin{tabular}{cccccc}
\hline PF & 23.0 & 43.9 & 3.8636 & 18.64 & 7.86 \\
B-PF & 23.6 & 43.5 & 3.7649 & 23.12 & 7.87 \\
\hline
\end{tabular}

It can be clearly noted that the 002 diffraction peak of C-B-PF, at $2 \theta=23.6^{\circ}$, has the tendency to shift to the larger angle direction compared with that of C-PF. The $\mathrm{d}_{002}$ values of two carbonized products are both higher than $3.5000 \mathrm{~nm}$, exhibiting glassy carbon character. However, the $\mathrm{d}_{002}$ value in the C-B-PF sample decreases $(3.7649 \mathrm{~nm}$ ) compared to that of the C-PF sample (3.8636 $\mathrm{nm}$ ), suggesting the presence of boron in a substitutional position. And the order degree of the pyrolyzated product is also improved. Moreover, the $\mathrm{L}_{c}$ and $\mathrm{L}_{\mathrm{a}}$ values for C-B-PF are both higher than that of C-PF. This indicates that the growth of crystallite is enhanced by the existence of boron. The incorporation of boron into carbon lattice results in an increase of crystallite height and decrease of interlayer spacing.

\section{Conclusion}

By means of TG-DTG analysis, the temperature at the maximum decomposing rate of B-PF is $567^{\circ} \mathrm{C}$, an increase of $54^{\circ} \mathrm{C}$ compare to that of the unmodified phenolic resin. And the maximum pyrolysis rate of $\mathrm{B}-\mathrm{PF}$ is $5.44 \% / \mathrm{min}$, a decrease of $8.23 \% / \mathrm{min}$ compare to that of the unmodified phenolic resin. Moreover, the oxidative residues yield of the $\mathrm{B}-\mathrm{PF}$ at $1000^{\circ} \mathrm{C}$ is $20.48 \%$, which is also $17.99 \%$ higher than of PF.

The pyrolyzate of B-PF were further analyzed by XPS and XRD analysis. The analysis indicates that the boron element reacts with the air or oxygen-containing volatiles to generate $\mathrm{B}-\mathrm{N}$ bond and boron oxides at elevated temperatures. The degree of graphitization of the phenolic resin is also improved owing to boron incorporation. And the crystal size of C-B-PF increases from $18.64 \mathrm{~nm}$ (C-PF) to $23.12 \mathrm{~nm}$.

\section{References}

[1] Jiang $\mathrm{H}$ Y, Wang $\mathrm{J} \mathrm{G}$, Wu S Q, et al. The Electrical Resistivity of $\mathrm{B}_{4} \mathrm{C}$ Modified Phenol-Formaldehyde Resin Matrix Composite Materials Pyrolyzed at Different Temperatures[J]. Advanced Materials Research, 2012, 583: 36-39.

[2] Shen S H, Zhang Y, Liu Y J. Kinetic Study of Titanium-Modified Phenolic Resin Curing Process by DSC Analysis[J]. Advanced Materials Research, 2012, 396: 1640-1644.

[3] Wang J, Jiang N, Jiang H. Micro-structural evolution of phenol-formaldehyde resin modified by boron carbide at elevated temperatures[J]. Materials Chemistry and Physics, 2010, 120(1): 187-192.

[4] Abdalla MO, Ludwick A, Mitchell T. Boron-modified phenolic resins for high performance applications. Polymer 2003;44(24).

[5] P. Byung-Dae, R. Bernard, Y.S. Kim, W.T. So, Effect of synthesis parameters on thermal behavior of phenol-formaldehyde resol resin, J. Appl. Polym. Sci. 83 (2002) 1415-1424.

[6] Hoard J, Hughes R, Muetterties E. The chemistry of boron and its compounds. New York: Wiley; 1967.

[7] Pilato L, editor. Phenolic resins: a century of progess. Heidelberg, Germany: Springer-Verlag Press; 2010. 